\title{
The Ecological Footprint and Driving Force Measurement Analysis of the Xinjiang Akesu Area Based on Gray model
}

\author{
Fangfang Han $^{1}$ Jing Shi $^{1, *}$ \\ ${ }^{1}$ The University of Tarim School of Economics and Management, Alar, 843300
}

\begin{abstract}
Keywords: The Aksu Region; Ecological Footprint; The Ecological Deficit; Grey Model
\end{abstract}
\begin{abstract}
Akesu area is located in the south of the Tianshan Mountains in the Xinjiang Uygur Autonomous Region, fragile ecosystems, land resources and the scarcity of water resources available, frequent environmental pollution and natural disasters of Akesu regional economic development is slow and restricts the development of the process of urbanization. In this paper, by using the ecological footprint theory, and using grey model to calculate the ecological footprint of Xinjiang 2008-2015 in Akesu over the years and the development trend is forecasted The results showed that: in 2008-2015 years, the per capita ecological footprint increased from $3.3879 \mathrm{hm}^{2} /$ in 2008 to $5.588 \mathrm{hm}^{2} /$ in 2015 over the same period; per capita decreased from $2.580646 \mathrm{hm}^{2} /$ to $2.3792 \mathrm{hm}^{2} /$ ecological carrying capacity, ecological deficit per capita increased from 0.807254 $\mathrm{hm}^{2} /$ in 2008 to $3.2088 \mathrm{hm}^{2} /$ in 2015, a growing trend. At the same time according to the per capita ecological footprint research area of the 2017-2025 forecast and the per capita ecological carrying capacity, ecological deficit per capita in 2025 obtained the study area will be increased to $12.70542 \mathrm{hm}^{2}$, indicating that the current Akesu area in a sustainable development of the state and state of charge of the ultra negative ecological region called the local government departments to take effective measures to actively develop ecological. The economy and the construction of ecological civilization are in order to realize the coordinated development of resources, environment and the regional economy.
\end{abstract}

\section{Introduction}

With the acceleration of urbanization and industrialization, the transformation of mankind on the surface is more and more intense, the huge economic losses caused by the destruction of the ecological environment, the vicious circle of sudden accidents, the past, local and individual environmental problems gradually to the global, Compound change. Xinjiang Aksu area is located in the southern foot of the Tianshan Mountains in Xinjiang Uygur Autonomous Region, the northern edge of the Tarim Basin, is located in the center of southern Xinjiang, is an important point of communication between the north and south of the Tianshan Mountains, but also the national "area along the way" construction of the core area. However, in recent years, due to the excessive production and living behavior of local residents in Aksu area, the area has been faced with a series of ecological and environmental problems such as aggravation of soil and water loss, aggravation of land desertification, deterioration of water resources environment and increasing environmental pollution. These problems have become a constraint Rapid development of the bottleneck problem.

The ecological footprint theory is a new approach proposed by Canadian eco-economists William and Wackernagel M. [1-2] in the early 1990s to measure the degree of sustainable development, which can visually reflect the area The development of economic and social development of natural resources, the determination of human consumption needs are within the scope of ecological load, is the study of regional ecological capacity of one of the effective tools [3]. International research on ecological footprint can be traced back to the 1970s. Hadin (1968) proposed the "commons theory of the commons" for us to clarify how public resources are over-consumed; Vitousek estimates the net primary productivity of the natural system occupied by human beings; Borgstrom in 1967 proposed "virtual Acronym (Ghostacreage) "concept, Odum called" shadow area (Shadow area) ". In addition, the ecological footprint is now being applied to various fields: from global to national, regional to urban, community to family, business enterprises 
to individual travel activities. (1999) [5] applied the ecological footprint index theory and calculation method to the ecological footprint of China and the provinces (autonomous regions and municipalities) in 1999, and then the ecological footprint of the Chinese ecological footprint was introduced in China. (2013), Yang Yi (2015), An Bao Sheng (2014), and the ecological footprint of China and the provinces (autonomous regions and municipalities) were higher than those of the local ecological carrying capacity. Liu Dongyan (2016) [6-10] used the ecological footprint theory, model and calculation method to analyze the ecological footprint and ecological carrying capacity of Gansu, Shaanxi, Tibet and Beijing-Tianjin-Hebei regions respectively, and obtained the ecological surplus / (2011), Zhang Bo (2011), Guo Rongzhong (2015), Xiangxiu Rong (2016) [11-14] using the ecological footprint theory and method, using the measurement of the ecological development of the deficit, and put forward the corresponding policy recommendations; (2010), Qin Jun (2010), Zhang Yi (2013), and the development trend of the ecological footprint and the carrying capacity of the study area were analyzed. Zhou Jing (2012), He Aihong (2013) use the Ecological Footprint Model to Analyze the Ecological Footprint Based on the Ecological Footprint Model Based on the Land Resources, Mineral Resources and Water Resources. Xinjiang, Nanjing and Ningxia put forward the countermeasures and suggestions to improve the regional sustainable development ability. Most of the relevant research in our country is concentrated in the middle and eastern regions. The relevant research results in Xinjiang are not rich. For the special situation of the Tarim River Basin, there are many studies on ecological fragility, extensive economic development and relatively backward areas.

In this paper, based on the ecological footprint model in the Aksu area of southern Xinjiang, this paper analyzes and evaluates the sustainable development of the Aksu area on the basis of calculating the per capita ecological footprint and per capita available ecological carrying capacity in the Akesu area from 2008 to 2015 The ecological footprint of the Aksu area in 2017 to 2025 was forecasted, and the ecological carrying capacity of the Aksu area was estimated, and the ecological carrying capacity and the ecological deficit were quantified by the per capita ecological footprint and the per capita ecological capacity forecasting model based on the GM $(1,1)$ gray forecast. To determine the current state of sustainable development in the Aksu region, with a view to the Aksu region future human survival and socio-economic development to make scientific planning and recommendations for the government or relevant departments to develop policies and planning to provide a scientific and rational basis. The results of the study can reflect the resource consumption intensity of the Aksu area and reflect the resource supply capacity and the total resource consumption in the Aksu area, revealing the ecological threshold of human survival.

\section{Research Methods}

Ecological Footprint / Bearing Capacity. The calculation of ecological footprint has formed a relatively complete set of system methods. The core of the ecological footprint is to assess the impact of human beings on the ecosystem in order to maintain the amount of resources consumed by human beings in order to maintain their own survival; their calculations are based on the following two basic facts: First, humans can determine their own consumption The amount of waste generated by most resources; and second, these resources and wastes can be converted into corresponding bio-productive land. "Ecological production land" is the most common basis of ecological footprint. According to the production form and production content, the global ecological productive land can be divided into fossil energy, cultivated land, pasture, woodland and construction land and water six categories. In the specific calculation, the consumption of various biological or fossil energy are according to a certain proportion of its corresponding land area, ecological footprint and ecological carrying capacity of the formula is as follows:

$$
\mathrm{EF}=\mathrm{N} \times \mathrm{ef}=\mathrm{N} \times \sum \mathrm{r}_{\mathrm{t}} \times \mathrm{A}_{\mathrm{t}}=\mathrm{N} \times \sum \mathrm{r}_{\mathrm{t}} \times\left(\mathrm{C}_{\mathrm{t}} / \mathrm{P}_{\mathrm{t}}\right)
$$

E-per capita ecological footprint; t-type of consumption items; rt-t items of consumption equilibrium factor; Ct-t per capita per capita; Annual consumption; Pt-t Item of the global average per unit area of consumption items. 


$$
\mathrm{EC}=\mathrm{N} \times \mathrm{ec}=\mathrm{N} \times \sum \mathrm{a}_{\mathrm{t}} \times \mathrm{y}_{\mathrm{t}} \times \mathrm{r}_{\mathrm{t}}
$$

E-ecological capacity; ec- per capita ecological carrying capacity; t-type of consumption; at-bio-productive area; yt-yield factor; rt-equilibrium factor.

Ecological Surplus / Deficit. Ecological footprint and ecological carrying capacity of the size of the ecological surplus or deficit to determine the difference between the two, if the ecological footprint is less than the ecological carrying capacity, the ecological surplus, and vice versa become the ecological deficit. The ecological surplus indicates that the total amount of biological resources in the region can support human needs and that the regional development model is in a relatively sustainable state [6]. On the contrary, the ecological deficit indicates that the demand for resources and environment in the region exceeds the maximum supply that can be provided by the environment. To maintain the consumption demand in this state, it is necessary to import insufficient resources from outside the area.

In the ecological footprint theory model, the ecological surplus / deficit is an important index to measure whether the ecological environment of the study area is sustainable. The formula is:

$$
\mathrm{ES}=\mathrm{EC}-\mathrm{EF}
$$

$\mathrm{EC}=\mathrm{EF}$, indicating that the area is in a state of ecological surplus, in other words, is the ecosystem security; if EC is the ecological footprint, EC is the ecological footprint, If $\mathrm{ES}<0$, then $\mathrm{ES}<\mathrm{EF}$, indicating that the area is in ecological deficit, in other words, the ecosystem is threatened; if $\mathrm{ES}=0$, then $\mathrm{ES}=\mathrm{EF}$, that is, the ecosystem supply and demand balance.

Data Sources. This paper is based on the Statistical Yearbook of Xinjiang in $2008 \sim 2016$ and the Statistical Yearbook of Xinjiang Aksu Region, Xinjiang Aksu Region Land and Resources, National Research Network Statistical Database and FAO Statistical Database, according to World Natural Science Foundation published global accounting standards The equilibrium factor and yield factor involved in the calculation method.

\section{Research Result}

Ecological Footprint. According to the formula of ecological footprint of formula (1), the ecological footprint of various types of land is obtained (see Table 1). For the convenience of calculation and comparison, the equilibrium factor used in the calculation is the land equilibrium factor proposed by WWF [7]: 2.21 for cultivated land and construction land, 0.49 for grassland, 1.34 for woodland, 0.36 for water and 1.34 for fossil energy. It can be seen from Table 1 that the ecological footprint of the Aksu area from 2008 to 2015 is on the rise gradually. Throughout the 8 years, the per capita ecological footprint increased from $3.3879 \mathrm{hm} 2$ / person in 2008 to $5.588 \mathrm{hm} 2$ / person in 2015, 39.4\%. Among them, the ecological footprint of cultivated land, grassland land, forest land, water area, fossil fuel land and construction land increased to a certain extent. From the changes of the ecological footprint of the six major types of productive land, it can be found that the ecological footprint of the grassland and fossil fuel land is more obvious, with the increase of $26 \%$ and $61 \%$ respectively. The ecology of cultivated land, forest land, water and construction land the magnitude of the change is relatively small. 
Tab.1 Per capita ecological footprint of Akesu in 2008-2015 years

\begin{tabular}{llllllll}
\hline \multicolumn{7}{c}{ All types of land types Ecological footprints } \\
\cline { 2 - 7 } Year & $\begin{array}{l}\text { Arable } \\
\text { Land }\end{array}$ & Grassland & Woodland Waters & Fossil fuels & $\begin{array}{l}\text { Construction } \\
\text { land }\end{array}$ & $\begin{array}{l}\text { Per capita } \\
\text { ecological } \\
\text { footprint }\end{array}$ \\
\hline 2008 & 0.7523 & 1.525 & 0.1225 & 0.1147 & 0.8508 & 0.0226 & 3.3879 \\
2009 & 0.8193 & 1.6067 & 0.1523 & 0.1661 & 1.0176 & 0.0191 & 3.7811 \\
2010 & 0.8030 & 1.7175 & 0.1902 & 0.179 & 1.1663 & 0.0222 & 4.0782 \\
2011 & 0.8749 & 1.8016 & 0.2273 & 0.215 & 1.6525 & 0.0423 & 4.8136 \\
2012 & 0.8844 & 1.9853 & 0.2721 & 0.2645 & 1.8828 & 0.0369 & 5.3260 \\
2013 & 0.7364 & 2.2764 & 0.3154 & 0.2735 & 2.035 & 0.0309 & 5.6676 \\
2014 & 0.7835 & 2.4405 & 0.3184 & 0.2682 & 2.3165 & 0.0362 & 6.1633 \\
2015 & 0.8394 & 2.0578 & 0.2101 & 0.2708 & 2.1772 & 0.0327 & 5.5880 \\
\hline
\end{tabular}

Ecological Carrying Capacity. According to the calculation formula of ecological carrying capacity of formula (2), the ecological carrying capacity of various types of land is obtained (see Table 2). In order to facilitate the calculation and comparison, the output factor index used in this paper adopts Wackernagel et al. [7]. The corresponding values of cultivated land, construction land, grassland and forest land are 1.66, 1.66, 0.19, 0.91. It can be seen from Table 2 that the ecological carrying capacity of the Aksu area in $2008 \sim 2015$ is decreasing gradually. Throughout the data of 8 years, the per capita ecological carrying capacity decreased from $2.580646 \mathrm{hm} 2$ / person in 2008 to $2.3792 \mathrm{hm} 2$ / And the ecological carrying capacity of cultivated land decreased from $1.3901 \mathrm{hm} 2$ / person to $1.1994 \mathrm{hm} 2$ / person. The ecological carrying capacity of grassland land decreased from $0.8417 \mathrm{hm} 2$ / person to $0.6894 \mathrm{hm} 2$ / person, and the land use, land use, Fossil fuel land, construction land, the ecological carrying capacity is slightly increased, this slight upward trend may be related to the local government in recent years for the protection of the ecological environment in the region are closely related. From the changes of the ecological carrying capacity of these six categories of productive land, it can be found that the ecological carrying capacity of cultivated land and grassland land is obviously changed by $16 \%$ and $22 \%$ respectively, while that of cultivated land, forest land, water and construction land the data of ecological carrying capacity change is relatively small.

Tab.2 Per capita ecological carrying capacity in Akesu area in 2008-2015 years

\begin{tabular}{llllllll}
\hline \multicolumn{7}{c}{ All types of land types per capita ecological carrying capacity } \\
\cline { 2 - 8 } Year & $\begin{array}{l}\text { Arable } \\
\text { Land }\end{array}$ & Grassland Woodland & Waters & Fossil fuels & $\begin{array}{l}\text { Construction } \\
\text { land }\end{array}$ & $\begin{array}{l}\text { Per capita } \\
\text { ecological } \\
\text { footprint }\end{array}$ \\
\hline 2008 & 1.3901 & 0.8417 & 0.1739 & 0.0007559 & 0.1738 & 0.0003053 & 2.580646 \\
2009 & 1.3595 & 0.8232 & 0.1701 & 0.0008252 & 0.1701 & 0.0004406 & 2.523999 \\
2010 & 1.3217 & 0.8003 & 0.1653 & 0.0008075 & 0.1653 & 0.0004569 & 2.453971 \\
2011 & 1.3113 & 0.7939 & 0.1640 & 0.0008109 & 0.1641 & 0.0005259 & 2.434655 \\
2012 & 1.3073 & 0.7916 & 0.1635 & 0.0008075 & 0.1635 & 0.0005328 & 2.427349 \\
2013 & 1.2751 & 0.7720 & 0.1595 & 0.0007970 & 0.1595 & 0.0004395 & 2.367325 \\
2014 & 1.2383 & 0.7498 & 0.1549 & 0.0007804 & 0.1549 & 0.0004972 & 2.299203 \\
2015 & 1.1994 & 0.6894 & 0.2447 & 0.0007892 & 0.2447 & 0.0003132 & 2.379200 \\
\hline
\end{tabular}

Ecological Deficit / Earnings Analysis. According to the formula of ecological deficit / surplus of formula (3), the ecological footprint and ecological carrying capacity of each type of land are compared (Table 3). It can be seen from Table 3 that the development trend of the per capita ecological footprint demand and the per capita ecological carrying capacity of the Aksu region in 
$2008 \sim 2015$ has been in the state of ecological deficit, and the ecological deficit has been increasing rapidly, and the deficit level is $134.87 \%$. At the same time, it is found that the ecological deficit is consistent with the change trend of the per capita ecological footprint demand. It can be seen that this is the result of the further increase of ecological demand while the ecological supply declines year by year. From the above data can be seen in the Aksu area of ecological development in the past eight years has been in an unsustainable state, the consumption of resources beyond the carrying capacity of the environment.

Tab.3 Comparison of ecological footprint per capita and ecological carrying capacity per capita in Akesu area in 2008-2015 years

\begin{tabular}{lllll}
\hline \multirow{2}{*}{ Year } & \multicolumn{3}{l}{ Per capita ecological Per capita ecological Ecological } & \multirow{2}{*}{ Deficit level $(\%)$} \\
& footprint & carrying capacity & deficit & \\
\hline 2008 & 3.3879 & 2.580646 & -0.807254 & 31.28108233 \\
2009 & 3.7811 & 2.523999 & -1.257101 & 49.80592306 \\
2010 & 4.0782 & 2.453971 & -1.624229 & 66.18778299 \\
2011 & 4.8136 & 2.434655 & -2.378945 & 97.71179079 \\
2012 & 5.3260 & 2.427349 & -2.898651 & 119.4163262 \\
2013 & 5.6676 & 2.367325 & -3.300275 & 139.4094600 \\
2014 & 6.1633 & 2.299203 & -3.864097 & 168.0624547 \\
2015 & 5.5880 & 2.379200 & -3.208800 & 134.8688635 \\
\hline
\end{tabular}

\section{Prediction of Ecological Footprint in Akesu Region from 2017 to 2025}

Predictive Methods. In order to predict the per capita ecological footprint of Aksu area from 2018 to 2015, we can use the GM $(1,1)$ model, as shown in the following equation (4): ecological capacity and ecological deficit.

$$
\begin{array}{r}
\hat{\boldsymbol{X}}^{(1)}(\mathrm{t}+1)=\left(\boldsymbol{X}_{(1)}^{(0)}-\frac{\mathrm{u}}{\boldsymbol{a}} \mathrm{e}^{-\mathrm{at}}\right)+\frac{\mathrm{u}}{\boldsymbol{a}}\left[\boldsymbol{X}_{(0)}^{(1)} \supset \boldsymbol{X}_{(1)}^{(0)}\right] \\
\hat{\boldsymbol{X}}^{(0)}(\mathrm{t})=\hat{\boldsymbol{X}}^{(1)}(\mathrm{t})-\hat{\boldsymbol{X}}^{(1)}(\mathrm{t}-1)
\end{array}
$$

Forecast Results. Based on the GM $(1,1)$ model $(4)$, the ecological deficit of the study area is forecasted from 2017 to 2025, and the forecast model is shown in Table 1.

Tab.4 Per capita ecological footprint and per capita ecological carrying of Aksu area

\begin{tabular}{|c|c|c|}
\hline Gray prediction model & Model test & $\begin{array}{l}\text { Relative } \\
\text { error \% }\end{array}$ \\
\hline $\begin{array}{l}\text { Per capita ecological } \mathrm{X}(\mathrm{t}+1)=0.948 \mathrm{e}^{0.1239 t}-3.193485(\mathrm{t}=1,2,3 \ldots \mathrm{n}) \\
\text { footprint }\end{array}$ & excellent & 2.98 \\
\hline $\begin{array}{l}\text { Per capita use of } \mathrm{X}(\mathrm{t}+1)=-0.916 \mathrm{e}^{-0.0257 t}+11.18363(\mathrm{t}=1,2,3 \ldots \mathrm{n}) \\
\text { ecological capacity }\end{array}$ & excellent & 0.21 \\
\hline
\end{tabular}
prediction model

It can be seen from Table 4 that the relative error value of the prediction model of per capita ecological footprint and per capita ecological carrying capacity is less than $3 \%$, which indicates that the prediction model has high reliability. Based on the data of the annual statistical yearbook of the Aksu area, the ecological footprint and ecological deficit of the Aksu area in 2017 were calculated to further verify the accuracy of the forecasting model. The calculated results show that the per capita ecological footprint of the Aksu area is $7.365175 \mathrm{hm} 2$ in 2017, Using the ecological carrying capacity of $2.584413 \mathrm{hm} 2$, the per capita ecological deficit is 4.78076 , and according to the results of the model of Table 5 shows that in 2017 the Aksu per capita ecological footprint and per capita available ecological carrying capacity will reach $7.53699 \mathrm{hm} 2$ and $2.25604 \mathrm{hm} 2$, the ecological deficit To $5.28095 \mathrm{hm} 2$, so the actual value and the predicted model of the relative error of the value of $2.27 \%$ and $12.7 \%$, respectively, indicating that the prediction model is more accurate. According 
to the model of Table 4, the per capita ecological footprint and per capita ecological carrying capacity of Aksu area in 2017 to 2025 are predicted. The results are shown in Table 5, and the ecological footprint and per capita ecological carrying capacity per capita in 2025 are 14.72816 $\mathrm{hm} 2$ and $2.02274 \mathrm{hm} 2$, respectively. It is clear that a series of effective measures must be taken to improve land productivity, reduce energy consumption, clean energy, change existing economic development models, and increase scientific and technological innovation. Otherwise, the ecological deficit in the Aksu area will continue to increase and the sustainable development situation will deteriorate further.

Tab.5 Predicted results

\begin{tabular}{llll}
\hline Year & Ecological footprint & Ecological carrying capacity & Ecological deficit \\
\hline 2017 & 7.53699 & 2.25604 & 5.28095 \\
2018 & 8.19534 & 2.22547 & 5.96987 \\
2019 & 8.91119 & 2.19531 & 6.71588 \\
2020 & 9.68957 & 2.16556 & 7.52401 \\
2021 & 10.53594 & 2.13621 & 8.39973 \\
2022 & 11.45624 & 2.10726 & 9.34898 \\
2023 & 12.45693 & 2.0787 & 10.37823 \\
2024 & 13.54502 & 2.05053 & 11.49449 \\
2025 & 14.72816 & 2.02274 & 12.70542 \\
\hline
\end{tabular}

\section{Conclusion}

(1) From the ecological footprint, the ecological footprint of the Aksu area showed an increasing trend in 8 years, indicating that the population of the Aksu area has a growing demand for natural ecology. In all kinds of eco-production land, the demand for fossil fuel land is the largest, Grassland land in the second; in the land type changes in the trend point of view, the ecological footprint is constantly expanding trend.

(2) From the perspective of ecological carrying capacity, the carrying capacity of cultivated land and grassland in Aksu area is relatively large, which is determined by the production mode and resource utilization of Aksu region. In terms of the overall trend of changes in the area of ecological production land, the ecological carrying capacity decreased, indicating that the ecological service capacity of this area decreased year by year. Aksu region is China's Uygur ethnic minority areas, is the national economic and social security and stability of the key support area, has a unique political and economic status; agriculture and animal husbandry, agriculture-based functional orientation requires the region must provide to meet the needs of many ethnic minorities Living habits of the production and living elements, including adequate grassland resources, fossil fuels, etc., this series of requirements exacerbated the Aksu area ofecological carrying pressure.

(3) From the results of GM $(1,1)$ forecast model, the per capita ecological footprint, per capita ecological carrying capacity and ecological deficit situation in the study area will be further deteriorated in 2017-2025. For this unfavorable ecological prospect, the local government The need to change the Aksu region over-reliance on mineral resources to develop the economy model, focusing on the development of knowledge-intensive industries, to reduce the non-renewable resources cannot be updated to the following aspects: Of consumption. Control population size and reduce population pressure on the environment. Change people's production and consumption patterns, and guide people to rational consumption to reduce the ecological deficit. Second, improve the ecological capacity of Aksu area; to continue to vigorously carry out land remediation work, the implementation of strict grassland, arable land resources protection measures. The implementation of the optimal allocation of resources and intensive use, improve resource utilization efficiency. Vigorously strengthen the ecological and environmental protection, ecological construction and environmental protection simultaneously, to further improve the level of unit land ecological capacity. 


\section{Acknowledgements}

Fund Project: National Social Science Fund Project "Green Development of Tarim River Basin Coupled by Vulnerable Ecological Environment and Poverty" (Item No: 16XMZ090)

\section{References}

[1]Rees W E. Ecological footprints and appropriated carrying capacity: what urban economics leaves out. Environment and Urbanization, 1992, 4(2):121-130

[2]Wackernagel $\mathrm{M}$, Onisto $\mathrm{L}$, Bello $\mathrm{P}$, et al. National natural capital accounting with the ecological footprint concept. Ecological Economics, 1999, 29(3): 375-390

[3] ZHU Jin-liang, LI Yu-ping, CAO Yun-long.Mechanical Analysis and Prediction of Ecological Footprint in Hebei Province Based on Gray Forecasting Model [J]. Journal of Arid Land Resources and Environment, 2011, (02): 24-28.

[4] Xu Zhongmin, Cheng Guodong, Zhang Zhiqiang. Ecological Footprint Method: A New Method of Quantitative Research on Sustainability - Taking Ecological Footprint of Zhangye Prefecture in 1995 as an Example [J] .Acta Ecologica Sinica, 2001, (09): 1484-1493

[5] Xu Zhongmin, Chen Dongjing, Zhang Zhiqiang, et al. Analysis of Ecological Footprint in China in 1999[J]. Journal of Soil Science, 2002, 39 (3): 441-445.

[6] CUI Xiuping, LV Jun, WANG Shan.Ecological and Environmental Impact Assessment and Regulation of Resource-based Cities in Ecologically Vulnerable Areas [J] .Development of Arid Land, 2015, (01): 148-154.

[7] ZHENG Hui, SHI Pei-jiu, HE Juan-juan.Study on Dynamic Analysis of Ecological Footprint and Ecological Carrying Capacity in Gansu Province [J]. Journal of Arid Land Resources and Environment, 2013, (10): 13-18.

[8] YIN Chun-xue, LI Feng, QIAN Yi, WANG Jie.Preparation of Comprehensive Assessment of Ecological Security in Changsha Based on GM (1,1) Model [J]. Environmental Science and Technology, 2012, (S1): 373-378.

[9] Zhou Jian, Liu Zhancai.Study on ecological security early warning and regulation in Lanzhou based on GM $(1,1)$ prediction model [J]. Journal of Arid Land Resources and Environment, 2011, (01): 15-19.

[10] Liu Mingyan, Wang Gang, Yu Bokang.Study on Ecological Security Strategy of Beijing-Tianjin-Hebei Based on Ecological Footprint [J]. Forestry Economy, 2016, (11): 9-15

[11] Zhang Bo, Liu Xiuli. Dynamic simulation and prediction of ecological footprint based on ARIMA model - Taking Gansu Province as an example [J] .Acta Ecologica Sinica, 2011, (20): 6251-6260.

[12] Guo Rongzhong, Shen Haijian, Yang Minhua.Study on Ecological Footprint and Ecological Carrying Capacity of Changsha City Based on Gray Model [J]. Journal of Soil and Water Conservation, 2015, (04): 195-200

[13] Xiang Xiu-Rong, Pan Tao, Wu Shao-Hong, et al.Evaluation and Prediction of Ecological Carrying Capacity of Northern Slope Economic Zone Based on Ecological Footprint [J]. Geography Research, 2016, (05): 875-884

[14] Han Shu, Shi Qingdong, Yu Yang, et al. Calculation and Analysis of Water Footprint in Xinjiang from 1999 to 2009[J]. Arid Geography, 2013, (02): 364-370. 
[15] Wang Xinghua, Mu Mingxin, Wang Shutao, et al.Study on sustainable development capacity and potential conversion of land resources based on ecological footprint [J] .Acta Ecologica Sinica, 2010, (14): 3772-3783.

[16] Gong Ji-ping, Pan Jing-hu, SHI Pei-ji.Study on sustainable development of Gansu Province based on ecological footprint and gray correlation degree [J]. Journal of Soil and Water Conservation, 2011, (02): 198-201.

[17] Deng Mingjiang. Xinjiang ten water eco-environmental protection objectives and countermeasures[J]. Arid Geography, 2014, (05): 865-874.

[18] He Aihong, Wang Yilong, to the party, etc. Based on the ecological footprint of the Ningxia Hui Autonomous Region sustainable development evaluation[J]. Arid Geography, 2013, (05): 906-912.

[19] Wang Guo - gang, Yang De - gang, Qiao Xu - ning, et al.Analysis of Xinjiang 's regional eco economic sustainable development capability based on ecological footprint model [J]. Glacier Frozen Soil, 2009, (05): 969-975.

[20] Gao Biao, Cui Fengyu.Study and prediction of dynamic change of ecological footprint and ecological carrying capacity in Jilin Province [J]. Soil and Water Conservation Research, 2012, (06): $105-110+116$.

[21] Zhou Jing, Guan Weihua.Study on sustainable development of Nanjing based on ecological footprint method [J] .Acta Ecologica Sinica, 2012, (20): 6471-6480. 